\title{
Business Process Integration And Supply Chain Networks
}

William C. Johnson, (E-mail: billyboy@huizenga.nova.edu), Nova Southeastern University

Kevin P. McCormack, President of DRK Research and Consulting LLC, Birmingham, Alabama

\begin{abstract}
Given the dot-com collapse and the recent Enron bankruptcy, one might conclude that the promises of the so-called new economy have been overstated. Yet, in spite of the litany of failed Internet pure plays and Enron's unexpected demise, the Internet has transformed the way the business is being conducted. Yes, the basics still matter and cost-cutting is appropriate, but today it must be achieved along with unprecedented business-model innovation and corporate agility.

Witness the way many traditional firms are still thriving and succeeding by transforming their core business architectures around the Net. The Internet is slashing the cost of sharing knowledge, collaborating, and meshing business processes among supply chain partners. Valued-added communities are replacing traditional vertically integrated industries. These value added communities are external networks that cover both company and supply chain processes, such as financial, marketing, accounting and human resources services. Smart companies are focusing on their core competencies and outsourcing the remainder of their non-essential processes.
\end{abstract}

The traditional vertically integrated corporation is no longer the most effective vehicle for value creation. Ford was the quintessential example of this. At one point, the company owned steamships, power plants, forests and virtually every other input critical to building an automobile. The vertically integrated structure worked well for auto manufacturers for a time to achieve scale economies and productivity. But these companies have squeezed out about as much productivity as they can.

In today's networked economy, one company makes the car's wheels, another makes the engine, another makes the seats and another makes the body all of which flow through the value added community that the auto company created. In the end, the auto company and the consumer both benefit. The automobile consumers get a better quality product, delivered precisely when and how they want it, at a much better cost. The auto company can respond to customers far more quickly than ever before.

We strongly believe that the "glue" for building these networked communities is a business process orientation (BPO), a concept introduced in one of our earlier books, which serves as a powerful organizing principle for firms competing in the networked economy. BPO is not simply a new business fad, but an entirely new way of thinking or viewing an organization. Nor is BPO simply a new business operations strategy, but rather broad framework for organizing work and information flows that ultimately help an organization build superior customer value. Corporate survival in the Internet economy will depend both on the effectiveness of internal processes and their integration with supply chain customers. Supply chain management will serve as the coordinating mechanism for process integration among supply chain partners. Competitors can match individ-ual processes or activities but can't match the integration or "fit' of these activities In this paper,we present empirical evidence showing that building a process-oriented organization results 


\begin{abstract}
Readers with comments or questions are encouraged to contact the authors via email. in improved business performance. We also propose that BPO can be successfully applied to supply chain networks and argue that value is created in the networked economy based on the alignment of supply chain processes.
\end{abstract}

\title{
1. Literature Review
}

\subsection{Business Process Orientation}

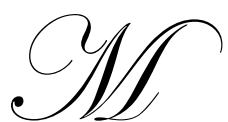

ost of what has been written about business process orientation during the last two decades is in the form of success stories concerning new forms of organizations. Although empirical evidence is lacking, several examples of these new forms have emerged during this period that have been presented as high performance, process oriented organizations needed to compete in the future. Leading thought leaders such as Deming, Porter, Davenport, Short, Hammer, Byrne, Imai, Drucker, Rummler-Brache and Melan have all defined what they view as the new model of the organization. Developing this model requires a new approach and a new way of thinking about the organization, which will result in dramatic business performance improvements. This "new way of thinking" or "viewing" the organization has been generally described as business process orientation.

During the 80 's, Michael Porter introduced the concepts of interoperability across the value chain and horizontal organization as major strategic issues within firms. ${ }^{1}$ Edward Deming developed the "Deming Flow Diagram" depicting the horizontal connections across a firm, from the customer to the supplier, as a process that could be measured and improved like any other process. ${ }^{2}$ In 1990, two researchers, Thomas Davenport and James Short, proposed that a process orientation in an organization was a key component for success. ${ }^{3}$ In 1993, Michael Hammer, who led the Reengineering craze of this decade, also presented the business process orientation concept as an essential ingredient of a successful "reengineering" effort. Hammer described the development of a customer focused, strategic business process based organization enabled by rethinking the assumptions in a process oriented way and utilizing information technology as a key enabler. ${ }^{4}$ Dr. Hammer offers reengineering as a strategy to overcome the problematic cross-functional activities that are presenting major performance issues to firms. The apparent conflict between a functional focus (who I report to) versus a horizontal focus (who I provide value to) is offered by Hammer as being brought back in balance by adding a business process orientation to the organization.

The reengineering emphasis of the 90's was on business process performance and the horizontal nature of e-corporations. However, the focus was mostly internal. Today corporations are extending outside of their legal boundaries and building networks as a normal way of organizing. Not just vertical integration but partnering, functional outsourcing, business process outsourcing, alliances, and joint ventures are all yesterday's requirements for success. The new realities of business require greater flexibility, responsiveness, and lower transaction costs. A business process orientation helps firms realize these goals, through superior intra and inter-process integration. Today's success depends on both horizontal and vertical "virtual integration"

\subsection{Internal Organizational Factors and BPO}

Two internal organizational factors affected by BPO proposed are inter-functional conflict and interdepartmental connectedness. Inter-functional conflict is defined as tension among departments arising from the incompatibility of actual or desired responses and inter-departmental connectedness as the degree of formal and informal direct contact among employees across departments. An increase in conflict across functions is thought to be a negative internal organization factor. Incompatible goals and tension between individuals in different functions, sales and manufacturing for example, have been shown to negatively impact organizational performance. An increase in connectedness across departments as measured by the easy flow of communication between departments and a low level of tension between members of each department has been shown to contribute to improved organizational performance. ${ }^{5}$

Implementing BPO as a way of organizing and operating in an organization is proposed to improve internal 
coordination and break down the functional silos that exist in most companies. This increase in cooperation and decrease in conflict has been shown by research to improve both short term and long term performance of an organization

\subsection{BPO and Business Performance}

Organizational performance can vary greatly among companies competing in similar markets. Moreover, industries apply different performance metrics, making cross-industry comparisons difficult. For example, the retail industry uses rapid inventory turns as a key performance metric in measuring good performance while the defense industry defines good performance as something very different. For this reason, we selected a self-report rating system to measure overall performance of the organizations studied. Use of key informant self-ratings has been shown to be closely approximate quantitative measures of performance and can also be used to compare organizations in different industries. Research has also shown that key informants can accurately and honestly position their organizations on an objective performance scale. ${ }^{6}$ Using a 5-point rating scale, participants in our research were asked to rate their own organization's performance as well as that of their competitors

The overall long-term health of an organization can be predicted from the attitude of the members. Team spirit and feelings of "being in it together"--generally described as esprit de corps--have been shown to be the energy and glue of an organization. Esprit de corps is defined as a spirit of enthusiasm and devotion to a common cause among a group. This team spirit is the subject of thousands of leadership books, tapes and speeches. Unfortunately, the restructuring and downsizing of the 80 's and 90 's destroyed this spirit and organizations have spent many millions of dollars in an attempt to rebuild this team spirit. Many leadership heroes and gurus have made their reputation by building this spirit of enthusiasm and credit their success as a leader to this ability. Witness Southwest airlines, the number one airline in almost every performance and customer satisfaction measure, A strong esprit de corps instilled by their charismatic leader Herb Kelleher, has made Southwest profitable for 26 straight years with an average EBITDA margin of $22.6 \%,{ }^{7}$

\section{Methodology}

During the early 90's, the BPO concept had attracted significant practitioner and researcher interest and had been implemented in whole or in part in enough companies that a substantial experience pool was now available. The challenge, of course, was tapping this broad range of experience and distilling it down into a format that practitioners could use it easily understand.

The approach we took was to review the popular business press and to interview experienced practitioners and experts both in the U.S. and Europe to help define BPO and its major components. Various statistical data reduction techniques (domain sampling, coefficient alpha analysis, and factor analysis) were used to produce a more parsimonious measure of BPO and to elicit its major dimensions. ${ }^{8}$

Key informant research was used to investigate the process orientation of selected organizations in the United States during 1998. A key informant study is one that selects participants based on their level of understanding about a certain topic. In this case, early in the study, participants were selected on the basis of their understanding of the BPO topic and during the later phase of the study selection was based upon BPO understanding and their understanding of the organization to which they belonged.

Our research was divided into two phases. Phase I involved developing a valid measure of business process orientation (BPO). Phase II involved testing these measures using a large national sample by administering a self-assessment questionnaire to gather data from several judgmental samples (population selected based upon a certain criteria). 


\subsection{Phase 1 - Developing BPO definitions and measures}

The objective to Phase I was to generate a validated definition of BPO and produce a valid and reliable measurement tool to be used in future research. This effort began with the development of several definitions derived from an extensive review of the published literature on the subject. A list of 200 possible measures was also developed during this review. A Delphi technique was used by sending the preliminary questionnaire to several BPO experts around the world for a "reality" check. Feedback from this jury of experts was used to prune and refine the BPO measure.

In keeping with the Delphi approach, a list of questionnaire items recommended by the jury of experts was then distributed to several hundred practitioners for their review. The participants were asked to numerically rate each definition and candidate measure according to its relevance in defining BPO. The scale used was a five point likert scale with 1 being completely disagree with the relevance of the questions or measure and 5 completely agree. The results were then examined. The definitions and questions with the average relevance scores below a rating of three were removed form the list.

Once the data were collected and analyzed, a consensus of two definitions of business process orientation seemed to surface:

- An organization that is oriented towards processes, outcomes and customers as opposed to hierarchies."

- An organization that emphasizes process and a process oriented way of thinking."

These two definitions were then combined to most accurately represent the BPO construct. Thus, the final definition of BPO which was to be used in all future research can be stated as follows:

"An organization that, in all its thinking, emphasizes process as opposed to hierarchies with special emphasis on outcomes and customer satisfaction."

The list of measures resulting from this Delphi process contained 200 questions organized into five major categories, representing dimensions of a business process oriented organization including:

- A process view of the business,

- $\quad$ Structures that match these processes,

- Jobs that operate these processes,

- $\quad$ Management and measurement systems that direct and assess these processes and

- $\quad$ Customer focused, empowerment and continuous improvement oriented values and beliefs (culture)

This new list of questions or possible measures of BPO was again distributed to several hundred practitioners. The participants were asked to rate these items again using a 5-point Likert scale measuring agreement with the question in regard to the participant's organization. This scale consists of the following response categories:

- $\quad$ 1-completely disagree,

- 2-mostly disagree,

- 3-neither agree nor disagree,

- 4-mostly agree,

- 5-completely agree,

- $\quad$ And 8-cannot judge.

The data were collected and analyzed. Statistical data reduction techniques produced a much more "elegant" business process orientation measure, consisting of three broad dimensions and eleven survey questions out of the original 200 items. The three dimensions that comprised the final survey instrument were: Process jobs (PJ): Process Management and Measurement (PM) and Process View (PV). [Please refer to Appendix A to see the final version of the BPO questionnaire]. To assure the confidence in utilizing the BPO scale to accurately assess an organization's process orientation, a second phase involved refining scale's properties. 


\subsection{Phase 2 - Expanded Testing and Further Validation}

The objective of Phase 2 of this study was to further test and validate the definitions and measurements. This was accomplished in two ways. First, identical tests from phase 1 were performed on a larger sample to see if the results matched. Secondly, BPO was compared to several organizational variables to determine if the proposed relationship of BPO to these organizational variables actually matches statistical reality. The organizational impact variables examined were the conflict and connectedness between functions within and organization, the overall business performance of the organization and the overall feelings of esprit de corps in the organization. All of these organizational variables were thought to be logically linked to BPO. The logic of the BPO measures can be tested by examining at these relationships utilizing a "Does this make sense?" test. If BPO can be shown to increase or decrease in a way that tracks the increase or decrease of other organizational factors that have already been defined and tested then the BPO measures can be said to have a logical or face validity.

The relationship to these organizational factors will also be examined in greater detail in the following chapter. Figure 1 shows the variables that are proposed to relate to BPO in an organization.

Figure 1. BPO and Organizational Impact Variables.

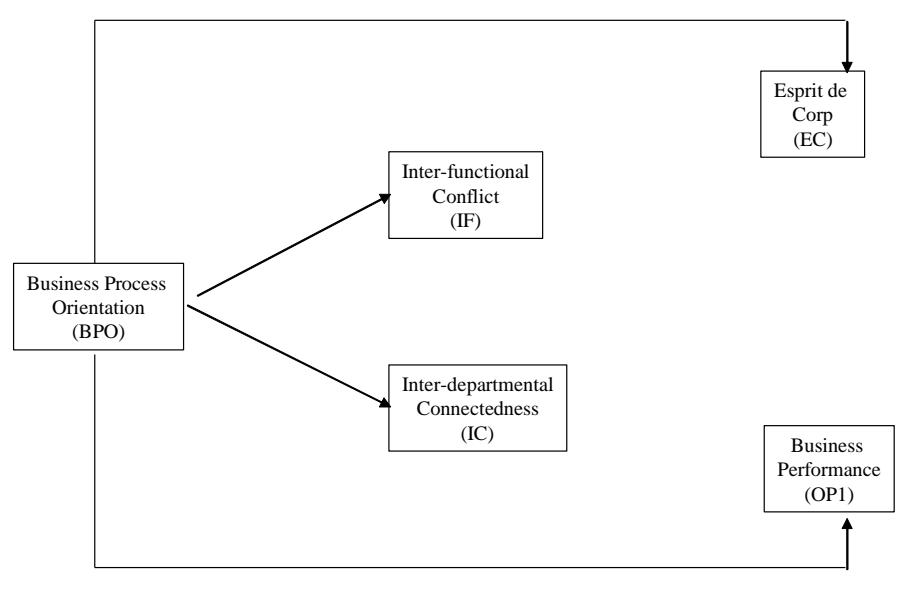

As a proposed "Does this make sense?" logic, it was thought that BPO would reduce conflict between functions, improve the connectedness between these functions, improve overall business performance and increase feelings of esprit de corps. All of these factors had well-established measures that could be included in the BPO survey instrument and thus were easily distributed with the BPO questions. ${ }^{9}$

For the final data gathering in phase 2, a judgmental sample of participants was selected from Hammer and Co. reengineering seminar attendee lists based upon company type Manufacturing firms in the U.S. being the unit of analysis. Data were also gathered from participants at a cross-company internal Motorola seminar.

Approximately 500 survey questionnaires were distributed by regular and electronic mail to the list of participants. A total of 115 responses were received and subject to identical statistical tests used in Phase I. Figure 2 shows the industries responding to the survey as very broad, with a strong concentration in the electronics. 
Figure 2. Industries Represented in the Sample

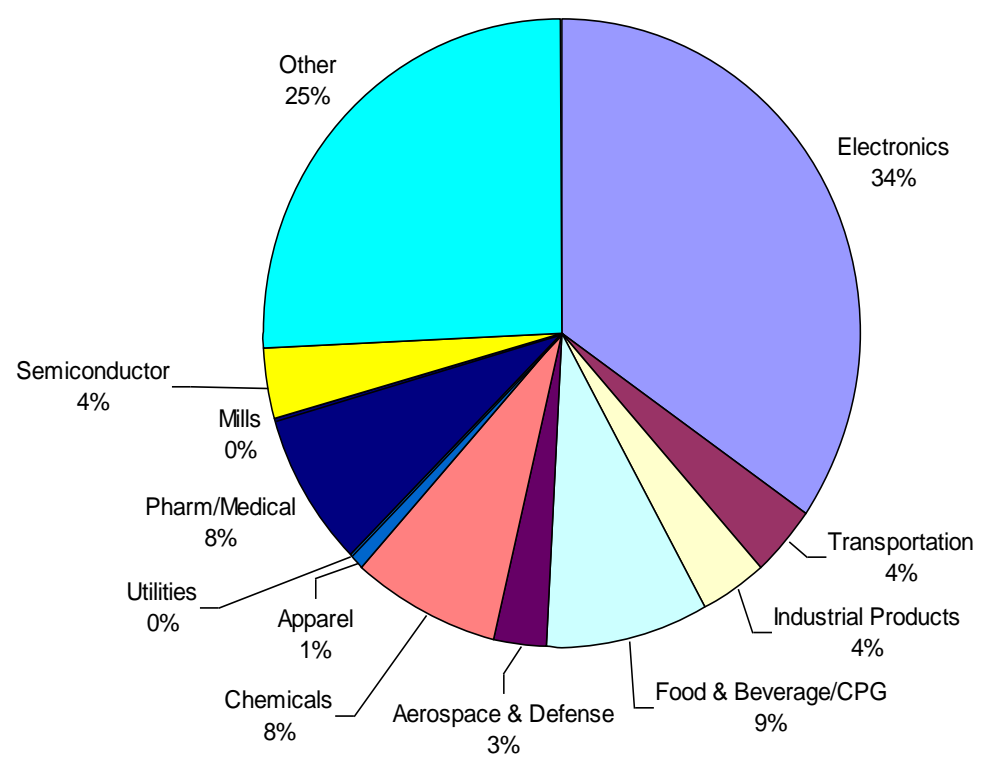

Again, using statistical data reduction techniques, the statistical relationships from phase 2 were compared to the results in phase 1 . The results in phase 2 duplicated the phase 1 results and thus provided the first level of validation for the measurements. The relationship statistics of the measures to each other and to overall BPO were almost identical thus providing validation that the measures were operating in a repeatable way.

For the second level of validation, whether the proposed relationships match, statistical tests were used to test the proposed relationships between BPO and the impact factors as shown in Figure 3. The relationships between BPO and esprit de corps and business performance were all strong, significant and in the right direction, meaning that when BPO increases business performance and esprit de corps increases. The relationships to interdepartmental (or inter-functional) conflict and connectedness were also strong and significant. Interdepartmental conflict was thought to have an inverse or negative relationship with BPO and this was also shown to be true.

The conclusions from phase 2 were that the measurement or survey instrument was actually measuring BPO and could provide repeatable results. Additional validation of the measures and the BPO concept was provided by the fact that the organizational relationships logically proposed as a "Does this make sense?" validation test came through in the statistical testing. Actual use of the BPO definition and measures seem, at least on the surface, to make sense. 
Figure 3. Regression Path Coefficients: BPO, Organizational Climate, Performance

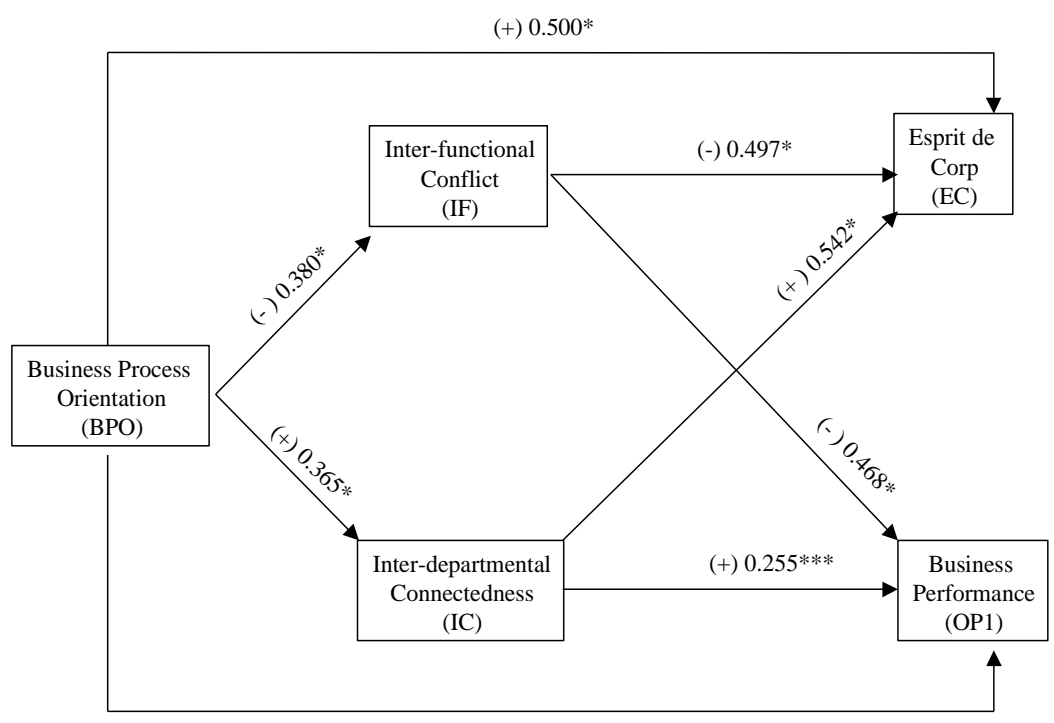

$(+) 0.279 * *$

Note: All numbers shown are Standardized Regression Coefficients of relationships.

Significance: . ** $\mathrm{p}<.003, * * * \mathrm{p}<.007, * \mathrm{p}<.001$

\section{Results}

We used a three-step process in order gauge the affect of BPO on organizational climate and performance. First we prepared a simple correlation matrix (see Table 1) in order to determine the strength of association between BPO and organizational climate and performance. We found that BPO and Esprit de Corps (EC) had a strong, positive correlation, indicating that BPO can dramatically influence the health of an organization as described by the employees' feelings of enthusiasm and devotion to a common cause.

We also found that BPO and interdepartmental connectedness showed a fairly strong positive correlation. This indicates that the cooperation across departments increases as BPO increases in an organization. On the other hand, BPO and inter-functional conflict exhibited a strong inverse relationship. Indicating that when BPO increases, conflict across functions decreases

These are important findings. May companies have spent millions of dollars of cross-functional teaming programs and consultants with the intent to improve inter- departmental cooperation and reduce conflict. Most companies have done this without changing their organization climate and/or structure. They have maintained the functional, departmental silos and attempted to overcome the conflicts by asking everyone to work on crossfunctional teams and "all get along". In some companies, a single person could be on twenty teams, an impossible situation with questionable results.

Finally, we wanted to see what effect BPO would have on overall business performance. Our results indicate a surprisingly strong relationship between BPO and overall performance. Considering all the factors that can potentially affect business performance, this finding is compelling. Business schools at most colleges and universities today focus on strategies and tactics that lead to successful business performance. How can one factor, a business process orientation of an organization, have this much impact on overall business performance? 
When analyzing our data according to each dimension (process jobs, process view, process management and measures) of business process orientation, the results yielded several interesting findings. First, the general relationship between all the components and inter-functional conflict is negative. This shows that as the BPO components of process management and measurement, process jobs and process view increase, inter-functional conflict decreases. Second, the relationship between PM (process management and measures) and all the impact factors is stronger than the other BPO components. This indicates that PM may be the most important component of BPO. Process oriented measures are, by definition, cross-functional and logically, this would contribute toward a common cause required for esprit de corps to occur. Lastly, process jobs (PJ) seems to be the next important component with process view (PV) the least important but still significant (See Table 1)

Table 1.

Correlation Matrix - BPO Dimensions and Outcomes

\begin{tabular}{|c|c|c|c|}
\hline Impact Factors & $\begin{array}{c}\text { Process Management and } \\
\text { Measures }\end{array}$ & Process Jobs & Process View \\
\hline Conflict & $-0.325^{* *}$ & $-0.231^{* *}$ & $-0.279^{*}$ \\
\hline Connectedness & $0.309^{* *}$ & $0.262^{*}$ & $0.187^{*}$ \\
\hline Performance & $0.319^{* *}$ & $0.206^{* *}$ & 0.111 \\
\hline Esprit de Corps & $0.428^{* *}$ & $0.313^{* *}$ & $0.308^{* *}$ \\
\hline$* \quad \quad \mathrm{P}<0.05$ & \multicolumn{3}{|l}{} \\
$* * \quad \mathrm{P}<0.01$ &
\end{tabular}

Is there a logical explanation for how these variables relate? For PM or process management and measures, it might be said that "what gets measured and rewarded gets done". Having horizontal or process measures that require groups of people to work together toward common goals should build a team spirit. Assuming the right measures were being used, this would positively affect the bottom line. Given the strong relationship between PM and overall performance (OP1) this seems to indicate that process oriented measures contribute to greater overall performance. The strong relationship to esprit de corps (EC) and the conflict and connectedness factors indicates that process oriented measures will decrease conflict, increase connectedness and result in an increase in the overall feeling of esprit de corps. Thus, process management and measures. seem to exert disproportionate influence, both on building a strong organizational culture (i.e., lower conflict, stonger sense of connectedness) while improving overall company performance.

Process jobs, the BPO factor exhibiting the next greatest influence, also seems to make sense. With "jobs" comes authority. With process oriented jobs comes "horizontal" or process oriented authority. This type of authority would span functional boundaries and, by definition of business process orientation, use this authority through direction and control to encourage employees to work together toward common goals. Employees reporting to a common manager are very likely to work toward common goals. Therefore, creating strong relationships that reduce conflict, increase connectedness and build esprit de corps all seem to make sense. The relationship to overall performance also makes sense. When there is unity of purpose around a leader, this energy usually translates to an improved bottom line.

The relationship of process view (PV) to the other organizational factors is the weaker when compared to the other BPO dimensions. Quite simply, process view is about documentation and understanding. Using a crossfunctional team to collectively view and describe process activities and responsibilities promotes esprit de corps by virtue of working side-by-side. It is a team building exercise. This activity and the clarity of roles can also reduce conflict and improve cooperation. Should this working together lead to new or redesigned processes, the result will be significantly higher connectedness within the organization.

The relationship of PV to overall performance seems a little weak. A possible explanation is that creating documentation and understanding by itself will not lead to higher overall business performance. Only the commitments between team members created during this documentation process can lead to performance improvements. 
This process includes not only documenting a process but a team agreeing upon what activities are performed, how they will be measured and who is responsible for the process outcomes. This system of agreements is the foundation for all the other things that need to be built to become business process oriented. It is always difficult to measure the direct contribution of a foundation, by itself, to performance.

\section{Conclusion}

A business process orientation is unequivocally crucial to long-term business success, yet to date no valid measure exists to assess its properties. Our research offers not only a robust definition of business process orientation but also a valid measure of this important construct.

This research has captured the factors most strongly affecting BPO in an organization. Based on our research, we can conclude that BPO can contribute to the overall performance of an organization by reducing conflict and improving inter-departmental cooperation. BPO has also been shown to improve esprit de corps in an organization. Companies structured into broad process teams rather than narrow functional departments should have less internal conflict and stronger team spirit. Furthermore, BPO is not dependent on a charismatic leader but on the fundamental organizational dynamics. It won't change when the leader leaves, as often happens. This provides a sustainable approach to improved performance and organizational health.

\section{Future Research}

During the past several years, the concept of supply chain management or SCM has been maturing both in terms of theory and practice. Terms such as integrated supply chain management, supply chain optimization and supply chain collaboration have become the focus and goal of many organizations in the U.S. and around the world. Global supply chain management has also emerged as a key competitive strategy. Just as we have seen how business process orientation positively influences organizational climate and performance, we propose that BPO can have the same effect in supply chain networks. Therefore, we posed the following question which could guide future research efforts: To what extent is supply chain management influenced by a business process orientation?

We propose studying the influence of BPO within industry supply chains, utilizing the Supply Chain Council's Supply Chain Operation Reference (SCOR) Model in conjunction with the BPO dimensions be conducted (see Figure 4) In order to determine the specific impact of BPO on supply chain management, the relationship between BPO components (i.e., process measures/management, process view and process structure) and the SCOR Model processes (i.e., plan, source, make, and deliver) should be explored. 
Figure 4. . BPO Components of SCM
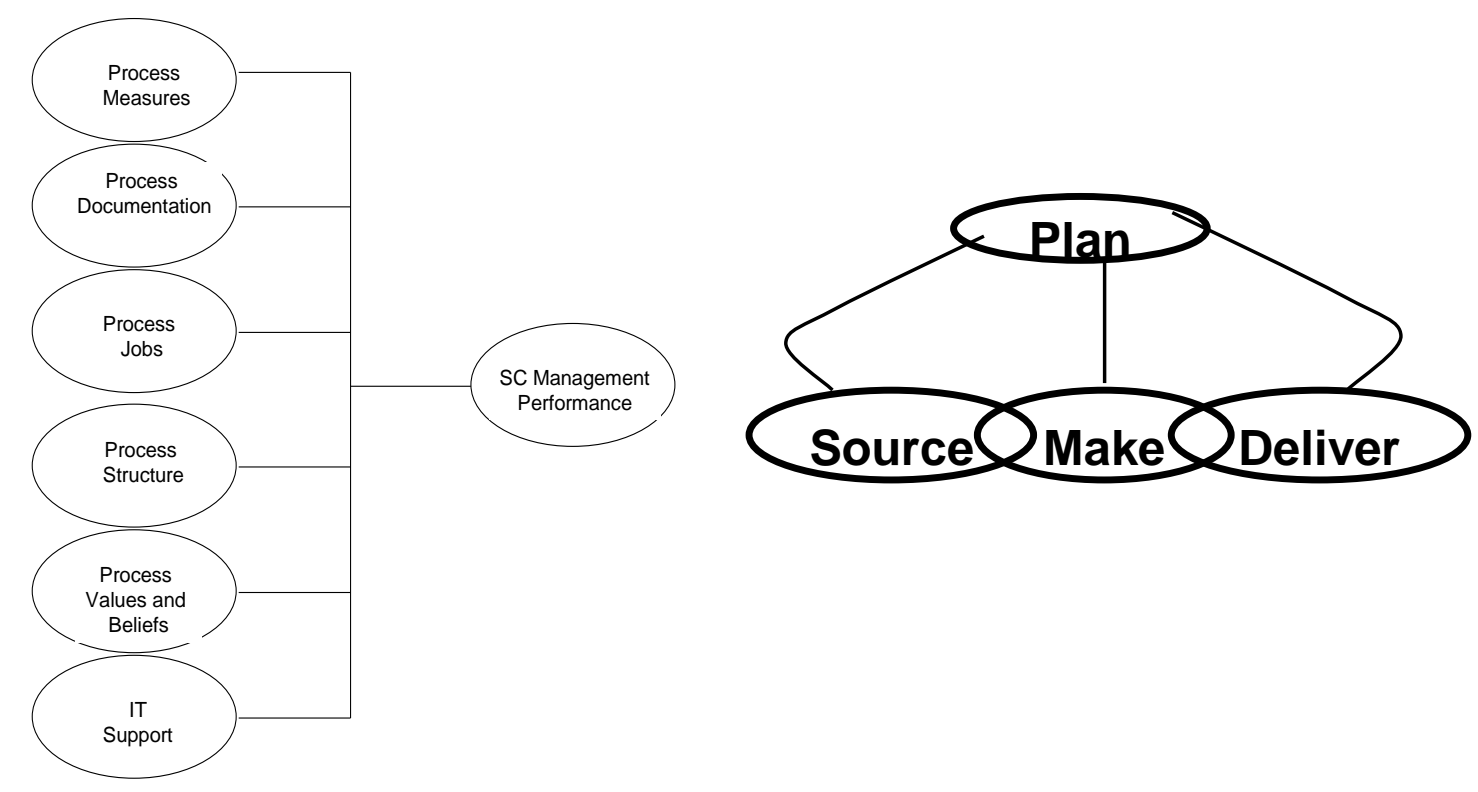

\section{Endnotes}

1 Porter, M.E. (1985), Competitive Advantage: Creating \& Sustaining Superior Performance. New York, NY: The Free Press.

2 Walton, Mary (1986). The Deming Management Method, Perigee Books. New York, NY.

3 Davenport, T.H, \& Short, J.E. (1990). "The new industrial engineering: Information technology and business process redesign". Sloan Management Review. 31. 11-27

4 Hammer, M. \& Champy, J. (1993). "Reengineering the Corporation: A Manifesto for Business Revolution". (1st ed.) New York, NY: HarperBusiness.

5 Ibid, p. 57

6 Rodgers, E.W. \& Wright P.M. (1998). "Measuring organizational performance in strategic human resource management: Problems, prospects and performance information markets". Human Resource Management Review. (Fall 1998).

7 "How Herb Keeps Southwest Hopping”. (1999) Money; New York; June, p. 61

$8 \quad$ McCormack, Kevin (1999). "The development of a measure of business process orientation and its link to the interdepartmental dynamics construct of market orientation". Dissertation Abstracts International, DAI-A 60/07, p.2589, Jan 2000.

9 Jaworski, B.J. \& Kohli, A.K. (1993). "Market orientation: Antecedents and consequences". Journal of Marketing, vol.57. (July 1993). 53-70. 